\title{
Risky Fertility Behavior, Breastfeeding Practices and Neonatal Mortality Risk: Evidence from Repeated Cross- Sectional Nationally Representative Data
}

\author{
Matthew A. Alabi, Grace E. Ihimekpen, and Taofeek A. Hassan
}

\section{ABSTRACT}

Background: Notwithstanding government efforts in improving maternal and child health, childhood mortality still remains a serious burden in the country, with neonatal mortality rate of 39 deaths and under-five mortality rate of 132 per 1,000 live births. This has implication on Sustainable Development Goals (SDGs) targeted towards reducing under-fiver mortality rate to 25 deaths per 1,000 live births by the year 2030. This study examined risky fertility behavior, breastfeeding practices, and neonatal mortality risk in Nigeria.

Materials and methods: This study involved the analysis of secondary data, Nigeria Demographic and Health Survey (pooled dataset of the three most recent surveys, NDHS, 2008, 2013 and 2018). The sample size was a weighted sample of 94,062 women aged $15-49$ years with 172, 252 live births for the ten years period. Descriptive statistics and cox-proportional hazard model were performed using Stata 14.1 software.

Results: Nearly two thirds $(64.0 \%)$ of births were high risk. The practice of breastfeeding among the women was quite poor, just $(39.5 \%)$ initiated breastfeeding within one hour of childbirth, though $\mathbf{( 7 4 . 0 \% )}$ reported breastfeeding their child for a minimum of 12 months. The independent effect of risky fertility behavior (RFB) was associated with elevated hazards of neonatal mortality, with the highest risk observed among births belonging to the multiple high-risk group $(H R=2.1, p<0.01)$. Adjusting for breastfeeding practices, maternal/child characteristics and maternal health seeking behavior was associated with elevated hazard of neonatal mortality with the highest hazard observed among births belonging to the multiple high-risk group $(H R=1.76, p<0.05)$. Other factors associated with elevated hazard for neonatal mortality are sex of the child, maternal level of education and breastfeeding duration.

Conclusion: RFB was associated with elevated hazard for neonatal mortality, even after adjusting for breastfeeding practices, maternal and child characteristics and maternal health-seeking behavior thereby lending credence to Mosley and Chen theory.

Published Online: November 30, 2020

ISSN: $2593-8339$

DOI: $10.24018 /$ ejmed.2020.2.6.581

Matthew A. Alabi *

Academy for Health Development,

Nigeria.

(e-mail: ayoalabi85@gmail.com)

Grace E. Ihimekpen

Medical and Dental Council of Nigeria, Nigeria.

Taofeek A. Hassan

College of Health Sciences, Obafemi

Awolowo University, Nigeria.

*Corresponding Author

Keywords: high risk, fertility behaviour, breastfeeding practices, neonatal mortality.

\section{INTRODUCTION}

Significant improvement has been made with regards to reduction in childhood mortality across the world and this has led to increased likelihood of millions of children under age five surviving. In addition, fast-tracking progress in the survival of children is urgently calling for more attention aimed at putting end to preventable deaths in southern and sub-Saharan Africa. In addition, recent statistics revealed at least one in every twelve children in sub-Sahara Africa will not live to celebrate his/her fifth birthday, when compared to an average of 1 death per 147 live births observed in developed countries of the world, making sub-Sahara Africa the region with the highest burden bearer of under-five mortality globally [1].

Although, few African countries like Ethiopia and Egypt appears to be making appreciable progress with regards to childhood mortality reduction, the same cannot be said about Nigeria. For instance, Egypt and Ethiopia have achieved $26.7 \%$ and $18.6 \%$ reduction in infant mortality between the period 2009-2014 and 2011-2016 respectively based on statistics from the most recent Demographic and Health Surveys in these countries [2], [3]. On the contrary, under-5 mortality in Nigeria increased from 128 to 132 , while neonatal mortality increased from 37 to 39 deaths per 1,000 live births between 2013 and 2018. The above statistics suggest childhood mortality in Nigeria still 
remains a burden despite various interventions (including programmes designed to increase proportion of births attended to by skilled health personnel, promotion of increased immunizations against vaccine-preventable diseases amongst others) put in place by the government [4].

Currently in Nigeria, Total Fertility Rate (TFR) is 5.3 and two thirds of births are classified as high-risk [4]. With the high childhood mortality still ravaging the country, more research attention is no doubt needed into causes of death during the childhood period, especially if the country is going to make any meaningful progress in the just adopted Sustainable Development Goals (SDGs) which is targeted towards reducing under-fiver mortality rate to 25 deaths per 1,000 live births by the year 2030 .

Besides, several social, cultural and religious factors shapes fertility behaviour in Nigeria and these factors continues to drive the high fertility level in the country. Nigeria is a heterogeneous country with about 374 different ethnic groups, although the Hausa/Fulani, Yoruba and the Igbo ethnic group are regarded as the major ethnic group [4]. More so, most of these ethnic groups emphasize the benefits of children and therefore support large number of children resulting in high fertility. Yet, it has been shown that countries with high fertility find it difficult to sustain programmes and policies needed for achieving sustainable growth and development.

The relationship between fertility and mortality has been well established in literature. A study in Uganda on the effects of high-risk fertility behaviour on the survivorship status of the child using the country's Demographic and Health Survey (DHS) data revealed mother's age at birth, birth intervals and parity were significant predictors of child survival [5]. Another study in Malawi on infant and child mortality revealed length of preceding birth interval was a significant predictor of infant and child mortality [6]. Studies have also shown differentials in breastfeeding practices and demonstrate significant association between breastfeeding practices and childhood mortality [7]-[10]. These studies found significant association between early initiation of breastfeeding and risk of infection-related mortality during childhood. Adapting the maternal factors of Mosley and Chen framework of childhood mortality, this study investigates risky fertility behavior, breastfeeding practices and neonatal mortality risk in Nigeria using evidence from repeated cross-sectional surveys. Most highrisk fertility studies [11-16] especially in Nigeria, have been measured using birth interval, age at first birth and birth order independently, thereby leaving a gap in studies relating composite risky fertility behaviour (combination of birth interval, age at first birth and birth order) with childhood mortality which necessitated this study.

\section{A. Theoretical Framework}

\section{Mosley and Chen (1984)}

The theoretical foundation for this study is the 1984 childhood mortality framework developed by Mosley and Chen [17]. This framework is very relevant to this study and has enjoyed wide applications in the study of childhood mortality in developing countries including Nigeria [18],
[19]. According to this framework, some sets of proximate factors were found to have a direct effect on childhood morbidity and mortality. This study however, adapts the maternal factors (one of the proximate determinants of childhood mortality) identified by the framework. These maternal factors are: age at first birth, parity and birth interval. Therefore, risky fertility behaviour (comprising of the Mosely and Chen maternal factors) was used to generate the principal explanatory variable.

\section{MATERIALS AND METHODS}

\section{A. Study Design and Population}

The study analyzed a nationally representative data pooled data of the three most recent Nigeria Demographic and Health Surveys (NDHS, 2008, 2013 and 2018). The survey used a cross-sectional research design. The population of the study comprises of women in the child bearing years that had at least one live birth five years period preceding the survey. Since DHS uses standardized methodologies and procedures across the different surveys, important questions relating to variables used in this study were framed in this manner.

\section{B. Sampling Technique}

A nationally representative sample was used for all the DHS surveys, covering the whole population residing in non-institutional residence in the country. The sample frame used for the survey was the list of Enumeration Areas (EAs) originally prepared the National Population Commission for the 2006 Population Census of Nigeria. The sample designed made provision for population and health indicators to be estimated at the national, regional and state levels. In addition, there was provision for computing indicators specific for the six regions of the country, 36 states and the Federal Capital Territory, Abuja. The sample was selected using a stratified three-stage cluster design in both rural and urban areas. Complete household listing was carried out including mapping exercise for each cluster, with the list of households serving as the sampling frame used for selecting the households. Households that were regular were all selected. Training was conducted for the NPC listing enumerators on the use of Global Positioning System (GPS) receivers for calculating coordinates of the sample clusters. The eligibility criteria for interview were all women of reproductive age 15-49 years who were either permanent residents of the households or visitors present in the households on the night before the survey.

\section{Data collection and Sample Size}

The survey used a model questionnaire designed by MEASURE DHS programme. The questionnaire elicits information from women in their reproductive years 15-49 years through a face-to-face interview. Technical and financial assistance for the survey was provided by ICF International through the USAID-funded MEASURE DHS program. Precisely, the kid recode dataset was analyzed. The sample size comprise of a weighted sample of 94,063 women aged 15-49 years (pooled from the three datasets 
2008, 2013 and 2018) with 172, 252 live births for the ten years period.

\section{Outcome Variable}

The outcome variable is neonatal mortality, defined as death within the first 28 days of life. The variable b7 (age at death) in the Nigeria Demographic and Health Survey dataset was used. This was however recoded by keeping for only deaths occurring within the first 28 days of life, while deaths after 28 days were right-censored.

\section{E. Explanatory Variables}

The main explanatory variables are risky fertility behaviour and breastfeeding practices. Risky fertility behaviour was generated from the NDHS dataset as a single variable categorized into four, namely: no risk, unavoidable risk, single high-risk and multiple high-risk. According to DHS classification, the first category (no risk) comprises of women who are not at risk at all; the second category (unavoidable risk) is defined as women whose age at first birth is in the age range 18-34 years; the third category (single high-risk) is defined as women exposed to just one risk i.e. those whose age at first birth is either below 18 years, above 34 years, birth interval less than 24 months or birth order above 3 ; fourth category (multiple high-risk) is defined as women exposed to more than one risk i.e. combination of at least two single high risk. For instance, the combination of age at first birth below 18 years and birth interval less than 24 months etc. Breastfeeding practices was measured using time of initiating breastfeeding after birth (immediately, within an hour, 1-23 hours and after 24 hours) and breastfeeding duration (less than six months, 6-11 months, 12-23 months and 24 months and above). Other explanatory variables used are: maternal education, defined as (no education, primary, secondary and higher), household wealth index derived using principal component analysis and categorized as poor, middle and rich. Place of residence (rural and urban), child's sex (male and female), birth type (single and multiple births), antenatal attendance (measured as attended antenatal, coded as Yes i.e. 1, otherwise no, coded 0 ) and place of delivery (whether delivery occurs in a health facility or outside health facility.

\section{F. Statistical Analysis}

Both descriptive (frequency count and percentages) were performed. Inferential analyses performed include chi square test and cox proportional hazard model (survival analysis). Survival analysis was considered more appropriate since the analytical interest is to study the time until an event occurs. Chi square test was used to test for association between categorical variables. Only explanatory variables that were highly significantly associated with outcome variable $(\mathrm{p}<0.002)$ were included into the multivariate model. Due to the complex nature of DHS design, the "svy" command was employed during analysis to adjust for clustering (enumeration areas) and sampling weight so as to ensure the data is nationally representative. Data analysis was performed using Stata 14.0 software.

\section{G. Ethics Approval and Consent to Participate}

Strict standards are usually maintained for protecting respondents of all DHS surveys. The survey was approved by Institutional Review Board (IRB) of ICF Macro International in the United States and the National Ethics Committee in the Federal Ministry of Health of Nigeria. National Population Commission obtained both oral and written consent from the survey participants.

\section{RESULTS}

\section{A. Socio-demographic Characteristics}

The socio-demographic characteristics of the women (Table 1) indicates greater percentage $28.1 \%$ were in the age group 25-29 years, followed by age group 30-34 years $22.1 \%$, while age group 45-49 accounted for the least proportion $2.9 \%$. Also, $(47.4 \%)$ had no formal education, only $(6.5 \%)$ had higher education. Majority $(65.3 \%)$ reside in rural area, with higher proportion $(35.1 \%)$ residing in the North-west and North-east $(17.4 \%)$ region. $60.5 \%$ of the women were affiliated to Islam religion, $38.2 \%$ practice Christianity, while women from the poorest household accounted for higher proportion $(45.8 \%)$.

\begin{tabular}{|c|c|c|}
\hline Maternal characteristics & {$[\mathrm{N}=94,062]$} & $\%$ \\
\hline \multicolumn{3}{|l|}{ Age Group } \\
\hline $15-19$ years & 4535 & 4.8 \\
\hline $20-24$ years & 18403 & 19.6 \\
\hline $25-29$ years & 26414 & 28.1 \\
\hline $30-34$ years & 20789 & 22.1 \\
\hline $35-39$ years & 14568 & 15.5 \\
\hline $40-44$ years & 6663 & 7.0 \\
\hline 45-49 years & 2688 & 2.9 \\
\hline \multicolumn{3}{|l|}{ Level of Education } \\
\hline No formal education & 44586 & 47.4 \\
\hline Primary & 17700 & 18.8 \\
\hline Secondary & 25614 & 27.2 \\
\hline Higher & 6162 & 6.6 \\
\hline \multicolumn{3}{|l|}{ Wealth Index } \\
\hline Poor & 43117 & 45.8 \\
\hline Middle & 18417 & 19.6 \\
\hline Rich & 32528 & 34.6 \\
\hline \multicolumn{3}{|l|}{ Region of Residence } \\
\hline North-Central & 12781 & 13.6 \\
\hline North-East & 16366 & 17.4 \\
\hline North-West & 33066 & 35.1 \\
\hline South-East & 8992 & 9.6 \\
\hline South-South & 9570 & 10.2 \\
\hline South-West & 13287 & 14.1 \\
\hline \multicolumn{3}{|l|}{ Place of Residence } \\
\hline Urban & 32649 & 34.7 \\
\hline Rural & 61413 & 65.3 \\
\hline \multicolumn{3}{|l|}{ Child's characteristics } \\
\hline \multicolumn{3}{|l|}{ Childs Sex } \\
\hline Male & 47,749 & 50.8 \\
\hline Female & 46,313 & 49.2 \\
\hline \multicolumn{3}{|l|}{ Birth Type } \\
\hline Single birth & 90,776 & 96.5 \\
\hline Multiple birth & 3,286 & 3.5 \\
\hline \multicolumn{3}{|l|}{ Fertility behaviour } \\
\hline \multicolumn{3}{|l|}{ Risky fertility behaviour } \\
\hline No Risk & 21,160 & 22.5 \\
\hline Unavoidable Risk & 13,012 & 13.8 \\
\hline Single High-risk & 35,988 & 38.3 \\
\hline Multiple High-risk & 23,901 & 25.4 \\
\hline \multicolumn{3}{|l|}{ Birth Interval } \\
\hline$<24$ months & 18,142 & 24.0 \\
\hline 24-35 months & 29,261 & 38.7 \\
\hline $36+$ months & 28,281 & 37.3 \\
\hline
\end{tabular}




\section{B. Breastfeeding Practices and Maternal Health-seeking Behaviour}

The breastfeeding practices of the women (Table II) revealed $73.9 \%$ breastfeed their child for at least 12 months, while higher proportion $38.1 \%$ also initiated breastfeeding between 1-23 hours after childbirth. Also, $37.4 \%$ of the women initiated breastfeeding immediately after birth. Likewise, higher percentage of the women $(38.7 \%)$ had birth interval of 24-35 month, $67.4 \%$ attended antenatal during pregnancy, while most of the births $(61.7 \%)$ were outside health facility. Substantial proportion $96.5 \%$ of the births were single birth, with sex of the child almost evenly distributed, male $(50.8 \%)$ and female $(49.1 \%)$. The trend in risky fertility behaviour suggest little or no decline, $(64.5 \%)$ in 2008, (64.0\%) in 2013 and $(63.2 \%)$ in 2018. The prevalence of early breastfeeding initiation (immediately after childbirth) appears to be rising, from $36.9 \%$ in 2008 to $43.7 \%$ in 2018 .

TABLE II: MATERNAL HEALTH-SEEKING BEHAVIOUR AND BREASTFEEDING

\begin{tabular}{ccc}
\multicolumn{2}{c}{ PRACTICES } & \\
\hline Maternal Health Seeking Behaviour & Freq & $\%$ \\
\hline Antenatal Visit*** & & \\
Yes & 38742 & 67.4 \\
No & 18728 & 32.6 \\
Place of Delivery** & & \\
Non-health facility & 57669 & 61.7 \\
Health facility & 34646 & 37.1 \\
Others & 1131 & 1.2 \\
\hline
\end{tabular}

\begin{tabular}{ccc}
\hline \multicolumn{2}{c}{ Breastfeeding Practices } & \\
\hline Time of initiating breastfeeding** & & \\
Immediately & 33985 & 37.5 \\
Within one hour & 1827 & 2.0 \\
1-23 hours & 34604 & 38.1 \\
After 24 hours & 20322 & 22.4 \\
Duration of breastfeeding** & & \\
Less than six months & 991 & 5.8 \\
6-11 MONTHS & 1534 & 8.9 \\
12-23 months & 12687 & 73.9 \\
24+ months & 1949 & 11.4 \\
\hline
\end{tabular}

**Missing and non-response excluded in analysis.

\section{Predictors of Neonatal Mortality}

Multivariate analysis involves performing cox proportional hazard model. Five models were presented. The first model (unadjusted) examined the influence of risky fertility behaviour (RFB) on hazard of neonatal mortality. The result showed increasing high-risk fertility was associated with elevated hazard for neonatal mortality, single high-risk $(\mathrm{HR}=1.46, \mathrm{p}<0.001)$ and multiple high risk $(\mathrm{HR}=2.08, \mathrm{p}<0.001)$. Adjusting for breastfeeding practices (model two), results in elevated hazard for neonatal mortality, single high-risk $(\mathrm{HR}=1.59, \mathrm{p}<0.001)$ and multiple high risk $(\mathrm{HR}=1.77, \mathrm{p}<0.001)$. While time of initiating breastfeeding did not influence risk of neonatal death, breastfeeding duration was significantly associated with risk of neonatal mortality. Model three adjusted for maternal and child characteristics. The result also showed elevated hazard for neonatal mortality, single high-risk $(\mathrm{HR}=1.37$, $\mathrm{p}<0.001)$ and multiple high risk $(\mathrm{HR}=1.88, \mathrm{p}<0.001)$. However, increasing level of education was associated with reduced hazard of neonatal mortality, secondary $(\mathrm{HR}=0.78$, $\mathrm{p}<0.05)$ and higher $(\mathrm{HR}=0.64, \mathrm{p}<0.05)$ education. Elevated hazard was found among births from women residing in rural area $(\mathrm{HR}=1.33, \mathrm{p}<0.05)$ and belonging to multiple birth $(\mathrm{HR}=4.32, \mathrm{p}<0.05)$, while reduced hazard of neonatal mortality was associated with the female sex $(\mathrm{HR}=0.81$, $\mathrm{p}<0.05)$. Furthermore, adjusting for maternal health-seeking behaviour (model four), elevated hazard for neonatal mortality was found, single high-risk $(\mathrm{HR}=1.60, \mathrm{p}<0.001)$ and multiple high risk $(\mathrm{HR}=2.16, \mathrm{p}<0.001)$. Risk of neonatal mortality was lower among women who attended antenatal care $(\mathrm{HR}=0.63, \mathrm{p}<0.05)$. The full model (model five) adjusted for breastfeeding practices, maternal and child characteristics and maternal health-seeking behaviour. The result showed multiple high-risk fertility was associated with elevated hazards $(\mathrm{HR}=1.76, \mathrm{p}<0.05)$ for neonatal mortality. Other factors that were significantly associated with risk of neonatal deaths are: breastfeeding duration and level of education.

\section{DISCUSSION}

The prevalence of risky fertility behaviour (RFB) was relatively high, comprising of (38.3\%) single high-risk birth and $(25.4 \%)$ multiple high-risk births. The study found risky fertility behaviour was significantly associated with hazard of neonatal mortality even after adjusting for breastfeeding practices, maternal and child characteristics and maternal health-seeking behaviour. Also, the study revealed breastfeeding practices among the women was rather poor. Less than half of the women initiated breastfeeding within one hour of child birth. Similarly, in the study by Waiswa, Peterson, Tomson and Pariyo [8] in Uganda to assess newborn care practices among women, it was found that all the babies were breastfed, though only about half were initiated within the first hour of birth, with a little above one third initiating breastfeeding within $1-6$ hours. Also, previous study conducted in Nepal by Devkotta and Bhatta [20] among women in a rural community revealed less than ten percent breast fed their babies within one hour, though all babies were breast fed. Also, about one third of the women threw away the first milk (colostrum), while most of the women did not give pre lacteals to their newborns. Nonetheless, most of the women breastfed their child for at least 12 months. In this study, the effect of place of delivery on neonatal mortality risk was not significant. This, however, may not be unconnected with the fact that nearly two thirds of the births were outside health facility.

\section{CONCLUSION}

This study has demonstrated significant effect of risky fertility behaviour on neonatal mortality risk in Nigeria. While time of initiating breastfeeding was not significantly associated with neonatal mortality, duration of breastfeeding significantly predicted neonatal mortality risk. Other important predictors of neonatal mortality risk in this study include sex of the child and maternal level of education. 


\section{POLICY IMPLICATION}

If the country is going to make any significant achievement with respect to the SDGs 2030 targets, it must prioritize programmes and interventions that will address factors accounting for high childhood mortality, including addressing the high prevalence of high risk fertility behaviour especially through improved maternal education and empowerment. This is in addition to strengthening the health system, so as to guarantee quality maternal health services that are capable of managing complications that could aggravate risk of neonatal and infant deaths as a result of high-risk birth.

\section{ACKNOWLEDGMENT}

The author would like to express his profound gratitude to ICF Macro, Calverton USA which collected the original data used in this study and also granted access to the data via the DHS archive.

\section{REFERENCES}

[1] United Nations. Interagency Group for Child Mortality Estimation (2015). Levels \& Trends in Child Mortality: Report 2017: Estimates Developed by the UN Inter-Agency Group for Child Mortality Estimation. United Nations Children's Fund.

[2] Central Statistical Agency (CSA) [Ethipia] and ICF, (2016). Ethiopia Demography and Health Survey 2016, Addis Ababa, Ethiopia and Rockville, Maryland, USA: CSA and ICF.

[3] Ministry of Health and Population [Egypt], El-Zanaty and Associates [Egypt], and ICF International, 2015. Egypt Demographic and Health Survey, 2014. Cairo, Egypt and Rockville, Maryland, USA: Ministry of Health and Population and ICF International.

[4] National Population Commission (NPC) [Nigeria] and ICF. (2019). Nigeria Demographic and Health Survey 2018 Key Indicators Report. Abuja, Nigeria, and Rockville, Maryland, USA: NPC and ICF.

[5] A. Isabirye (2012): The effects of high risk fertility behavior on child survival in Uganda. Doctoral Thesis dissertation, Makerere University.

[6] C. Lemani (2013). Modelling covariates of infant and childhood mortality in Malawi (Doctoral dissertation, University of Cape Town).

[7] J. Chaudhary, G.P., Dhungana, \& H.C. Ghimire, (2013). Factors affecting newborn care practices among Tharu mothers in selected Vilalge development committees of Chitwan distract. Journal of Chitwan medical college, 3(1), 42-45.

[8] P. Waiswa, S. Peterson, G., Tomson, \& G.W. Pariyo (2010). Poor newborn care practices-a population based survey in eastern Uganda. BMC pregnancy and childbirth, 10(1), 9.

[9] K.M. Edmond, C. Zandoh, M.A. Quigley, E.S. Amenga-S., OwusuAgyei, \& B.R. Kirkwood (2006). Delayed breastfeeding initiation increases risk of neonatal mortality. Pediatrics, 117(3), e380-e386.

[10] M.J. Sankar, B. Sinha, R Chowdhury, N. Bhandari, S. Taneja J. Martines, \& R. Bahl, (2015). Optimal breastfeeding practices and infant and child mortality: a systematic review and meta-analysis. Acta paediatrica, 104, 3-13.

[11] J.G. Cecatti P.B. Eloisa H. Milanez S.S. Morais J.P. Souza (2008): The Associations between Inter-Pregnancy Interval and Maternal and Neonatal Outcomes in Brazil. Volume 12, Issues 2, pp 275-281.

[12] J. Davanzo, L. Hale, A. Razzaque and M. Rahman (2008). The effects of pregnancy spacing on infant and child mortality in Matlab, Bangladesh: How they vary by the type of pregnancy outcome that began the interval. Population Studies, 62:2, 131-154, DOI: 10.1080/00324720802022089.

[13] S. Eventov-Friedman, R.Y. Zisk-Rony S. Nosko and B. Bar-Oz (2016). Maternal age and outcome of preterm infants at discharge from the neonatal intensive care unit. International Journal of Gynecology Obstetrics, Volume 132, Issue 2, Pages 196-199.

[14] J.C. Fotso, J. Cleland, B. Mberu, B., M. Mutua, \& P. Elungata, (2013) Birth Spacing and Child Mortality: An Analysis of Prospective Data
From The Nairobi Urban Health And Demographic Surveillance System. J. Biosoc Sci, 45(6), 779-798.

[15] S.O. Rustein, (2005). Effects of preceding birth intervals on neonatal, infant and U5 mortality and nutritional status in developing countries: evidence from the demographic and health surveys. Int J Gynaecol Obstet.

[16] A. Whitworth, and R. Stephenson, (2002). Birth spacing, sibling rivalry and child mortality in India. Social Science \& Medicine 55: 2107-2119.

[17] W.H. Mosley, and L.C. Chen (1984). "An analytical framework for the study of child survival in developing countries", Population and development review 10:25-45

[18] S.A. Adedini. (2013). Contextual Determinants of Infant and Child Mortality in Nigeria, University of Witwatersrand, Johannesburg, SA, PhD Thesis.

[19] S.A. Adedini., O.O. Clifford, D. Ononokpono, L. Ibisomi, C.E. Bob and E. Imasiku. (2012). "Regional inequalities in under-five mortality in Nigeria: a multilevel analysis." In Population Association of America Annual Meeting, pp. 1-32. 2012

[20] M.D. Devkota, and M.R. Bhatta, (2011). Newborn care practices of mothers in a rural community in Baitadi, Nepal. Health Prospect: Journal of Public Health, 10, pp.5-9.

Alabi M.A., MSc is a Demographer and Statistician, currently the Programme and Research Manager at the Academy for Health Development, Ile-Ife, Nigeria. His research area is in Maternal and Child Health. He is interested in investigating causes of death during childhood period and implication of high risk birth on maternal and child health.

Ihimekpen G.E., MB.Ch. B is a Medical Doctor, with the Lagos State Health Service Commission, Lagos Nigeria. She specializes in Family Medicine and Public Health with interest in affordable healthcare delivery, morbidity and mortality.

Hassan T.A., MB.Ch.B is a Medical Doctor and Public Health enthusiast. He currently works at the Obafemi Awolowo Teaching Hospital, Ile-Ife, Nigeria. He is passionate about sustainable healthcare delivery in Africa, promoting health equity and influencing Public Health Legislation in areas of Health Policy Financing and Planning. 